\title{
Soluble RAGE levels in plasma of patients with cerebrovascular events
}

\author{
Falcone Colomba ${ }^{1,2,3}$, Bozzini Sara ${ }^{2}$, D'Angelo Angela ${ }^{2}$ and Pelissero Gabriele ${ }^{3}$ \\ ${ }^{1}$ Department of Cardiology, Istituiti Clinici di Pavia e Vigevano, University Hospital, Pavia, Italy \\ ${ }^{2}$ Interdepartimental Center for Research in Molecular Medicine (CIRMC), University of Pavia, Pavia, Italy. \\ ${ }^{3}$ IRCCS San Donato Hospital, San Donato Milanese, Italy
}

\begin{abstract}
There is growing evidence implicating the participation of RAGE-ligand interaction in the development and progression of various immune-mediated disorders, including vascular disease. The aim of the present study was to evaluate the sRAGE plasma levels in patients with ischemic stroke or transient ischemic attack in order to identify a biomarker of differentiation in the genesis of these diseases. This study included 87 Caucasian subjects (50 males and 37 females) with cerebrovascular event. Plasma levels of sRAGE were determined using a kit for the immunoadsorption enzyme, commercially available. Our study showed that the plasma concentration of sRAGE is significantly lower in patients with ischemic stroke compared to patients with transient ischemic attack and to controls. This feedback appears to confirm that transient ischemic attack, in absence of documented organic pathology, does not seem to recognize the atheromasic origin as its primary cause. This analysis contributes information about the pathophysiology of vascular cerebral disease and, in particular, these results reaffirm strong prothrombotic and inflammatory components to the pathophysiology of stroke.
\end{abstract}

\section{Introduction}

Stroke is the third major cause of death worldwide and the leading cause of permanent disability; ischemic stroke (IS) alone accounts for $70-80 \%$ of all stroke [1]. Instead, Transient Ischemic Attack (TIA) is a brief episode of neurological dysfunction resulting from focal cerebral ischemia not associated with permanent cerebral infarction [2].

There is growing evidence implicating the participation of RAGEligand interaction in the development and progression of various immune-mediated disorders, including vascular disease $[3,4]$.

The Receptor for Advanced Glycation End-products (RAGE) is a multi-ligand member of the immunoglobulin superfamily ubiquitous present on epithelial, neuronal, vascular and inflammatory cells, usually expressed at low levels in homeostasis and to increased degrees at sites of stress or injury [5].

It is known that RAGE-mediated mechanisms play a role in ischemic myocardial injury through triggering RAGE-dependent cellular activation, inducing oxidative stress, and promoting inflammatoryproliferative responses leading to vascular dysfunction $[3,6]$. However, few studies have addressed pivotal roles of RAGE signaling in acute stroke. Activation of RAGE may play a role in neuronal damage and neuroinflammation associated with brain ischemia. Based on the evidence from animal studies and the presence of increased high mobility group box 1 protein (HMGB1, a RAGE ligand) in the serum of stroke patients, Mennini T at al. find that soluble RAGE (sRAGE) increase in serum after ischemic and hemorrhagic stroke and that the levels decrease with patient improvement [7]. The secreted isoform of the receptor for advanced glycation end-products (sRAGE), can neutralize the adverse effects of RAGE signaling by acting as a decoy.

The aim of the present study was to evaluate the sRAGE plasma levels in patients with IS and TIA in order to identify a biomarker of differentiation in the genesis of these diseases.

\section{Materials and methods}

\section{Study population}

This study included 87 Caucasian subjects (50 males and 37 females) with previous cerebrovascular event, consecutively recruited among subjects referred to the Department of Cardiology of University Hospital. The diagnosis of IS patients was confirmed and characterized by head magnetic resonance imaging or reported computed tomography exams (performed $\geq 24$ hours after stroke onset to clearly demonstrate the infarction region).

The $56 \%$ of the patients included in the study presented at least one angiographically documented coronary stenosis, ( $\geq 75 \%$ stenosis); $6 \%$ had atrial fibrillation, the $25 \%$ presented a dilated cardiomyopathy and the $13 \%$ of patients did not have any cardiovascular disease.

Patients underwent to an accurate examination and a gathering of physiological, pathological, remote and proximal, familiar and pharmacological anamnestic data. Patients with infective diseases or chronic inflammation and patients and affected by renal failure or severe liver complications, cancer, or hematological disorders were excluded from the study. Cardiovascular risk factors were defined as follows: hypertension (systolic blood pressure $>140 \mathrm{mmHg}$ or

Correspondence to: Prof. Colomba Falcone, Department of Cardiology, Istituiti Clinici di Pavia e Vigevano, University Hospital, Via Parco Vecchio, Pavia, Italy, E-mail: colomba.falcone@unipv.it

Key words: soluble RAGE, transient ischemic attack, ischemic stroke

Received: December 12, 2016; Accepted: January 17, 2017; Published: January 20,2017 
diastolic blood pressure $>90 \mathrm{mmHg}$ or anti-hypertension therapy); family history of cardiovascular pathology (documented coronary artery disease in parents or siblings manifested before 60 years of age in men and 70 years of age in women); smoking was considered a risk factor if the patients had smoked more than three cigarettes a day for at least one year (patients were classified as: habitual smokers, ex smokers if they had quit smoking for at least four weeks but not more than 40 years or as non-smokers if they had never smoked or if they had quit smoking for 40 or more years before the study). Patients' lipid range (total cholesterol, LDL and HDL, triglycerides, defining hypercholesterolemia and hypertriglyceridemia as cholesterol and triglycerides plasma concentrations respectively higher than 200 $\mathrm{mg} / \mathrm{dL}$ and $150 \mathrm{mg} / \mathrm{dL}$ ) and patients' glycaemia (normal values were considered if less than $100 \mathrm{mg} / \mathrm{dL}$, reduced glycaemic tolerance if glycaemia was $100-110 \mathrm{mg} / \mathrm{dL}$ and diagnosed diabetes if the plasma concentration of glucose was $>126 \mathrm{mg} / \mathrm{dL}$ ) was considered.

The control subjects were 328 patients who visited the Department of Cardiology for a physical check-up. Controls were characterized by no history of ischemic stroke or transient ischemic attack; they were matched with patients by age and ethnicity.

All participants gave written informed consent. The study protocol is conformed to the guidelines of the Helsinki Declaration for human research and was approved by our local ethics committee.

\section{Measurements of soluble receptor of advanced glycation end products}

Venous blood samples were collected in Vacutainer tubes containing ethylenediaminetetraacetic acid as anticoagulant for determination of plasma levels of sRAGE. The samples were centrifuged at $1000 \mathrm{~g}$ for $30 \mathrm{~min}$ and immediately divided into aliquots. Finally, plasma and serum samples were frozen and stored at $-20^{\circ} \mathrm{C}$ until the analysis. All laboratory tests were performed in blind.

Plasma levels of sRAGE were determined using a kit for the immunoadsorption enzyme, commercially available (Quantikine, $\mathrm{R}$ \& D Systems), according to manufacturer's protocol. Briefly, a monoclonal antibody against sRAGE has been used to capture sRAGE from plasma. sRAGE captured was marked with a polyclonal anti-human sRAGE. After washing, the plates were incubated with streptavidin-HRP, developed on an appropriate substrate and OD450 was determined using a plate reading immunoadsorption enzyme. The measurements were made in duplicate and the results compared. The values of the coefficients of variation intra-and inter-determination were respectively less than $6 \%$ and $<8 \%$.

\section{Statistical analysis}

We used the Kolmogorov-Smirnov analysis to test if the continuous variables presented a normal distribution. The continuous variables were expressed by an average \pm standard deviation or by a median and interquartile range if data did not fall into a normal distribution pattern. The categorical variables were presented as frequencies and percentages. The differences between the groups were valued with the Student's t test for normally distributed variables, with Mann-Whitney's U Test for the not normally distributed variables, and with the Chi-squared test for the categorical variables. The correlations between the variables of our study were valued calculating the correlation coefficients according to Spearman analysis. Values of $\mathrm{p}<0.05$ were considered statistically significant.

\section{Results}

\section{Clinical and laboratory characteristics of patients and control subjects}

The main clinical and biochemical characteristics of the study participants are shown in (Table 1). Patients were more likely to be ever-smokers $(\mathrm{p}<0.01)$, diabetic $(\mathrm{p}<0.001)$ and hypertensive $(\mathrm{p}<0.0001)$ compared with controls. There were no significant differences in age, total cholesterol, $\mathrm{HDL}$ cholesterol, triglycerides and $\mathrm{C}$ reactive proteins levels between the two groups (Figure 1).

The concentration of sRAGE in plasma, expressed as median [IQ range] was significantly lower in patients with cerebrovascular disease [806 (441-1077) pg/mL] than in control subjects [1335 (936-1954) pg/ $\mathrm{mL}] ; \mathrm{p}<0.0001$.

\section{sRAGE concentration in patients with ischemic stroke and with transient ischemic attack}

Of the 87 patients recruited for the study, 64 (74\%) had previous TIA and 23 (24\%) had previous IS. In (Table 2) were shown the main clinical and biochemical characteristics of the study participants divided according to their pathologies. Patients with IS are more often male than patients with TIA. There were no significant differences in distribution of common cardiovascular risk factors, age, total cholesterol, HDL cholesterol, triglycerides, and glycaemia and C reactive proteins levels.

The concentration of sRAGE in plasma was significantly lower in

Table 1. Clinical and biochemical characteristics of the study participants.

\begin{tabular}{|l|c|c|c|}
\hline & $\begin{array}{c}\text { Patients } \\
(\mathbf{n = 8 7 )}\end{array}$ & $\begin{array}{c}\text { Control } \\
\text { subjects } \\
(\mathbf{n = 3 2 8})\end{array}$ & p value \\
\hline Age, $\mathbf{y}$ & $72 \pm 12$ & $63 \pm 8$ & $\mathrm{Ns}$ \\
\hline CAD, n (\%) & $49(56 \%)$ & 0 & \\
\hline Arrhythmic, n (\%) & $5(6 \%)$ & 0 & \\
\hline DCM, n (\%) & $22(25 \%)$ & 0 & $\mathrm{P}<0.0001$ \\
\hline None, n (\%) & $11(13 \%)$ & $328(100 \%)$ & $\mathrm{P}<0.01$ \\
\hline Ever-smoking, n (\%) & $43(49 \%)$ & $102(31 \%)$ & $\mathrm{P}<0.0001$ \\
\hline Hypertension, n (\%) & $66(76 \%)$ & $58(18 \%)$ & $\mathrm{P}<0.001$ \\
\hline Diabetes, n (\%) & $23(26 \%)$ & $33(10 \%)$ & $\mathrm{Ns}$ \\
\hline Total cholesterol, mmol/L & $5.19 \pm 1.14$ & $4.99 \pm 1.0$ & $\mathrm{Ns}$ \\
\hline Triglycerides, mmol/L & $1.48 \pm 0.79$ & $1.47 \pm 0.68$ & $\mathrm{Ns}$ \\
\hline HDL cholesterol, mmol/L & $1.24 \pm 0.31$ & $1.40 \pm 0.42$ & $\mathrm{P}<0.0001$ \\
\hline C reactive protein, mg/dL & $0.65(0.1-8.4)$ & $0.6(0.3-1.1)$ & \\
\hline sRAGE, pg/mL, median & $806(441-1077)$ & $1335(936-1954)$ & \\
\hline (IQrange) & & & \\
\hline
\end{tabular}

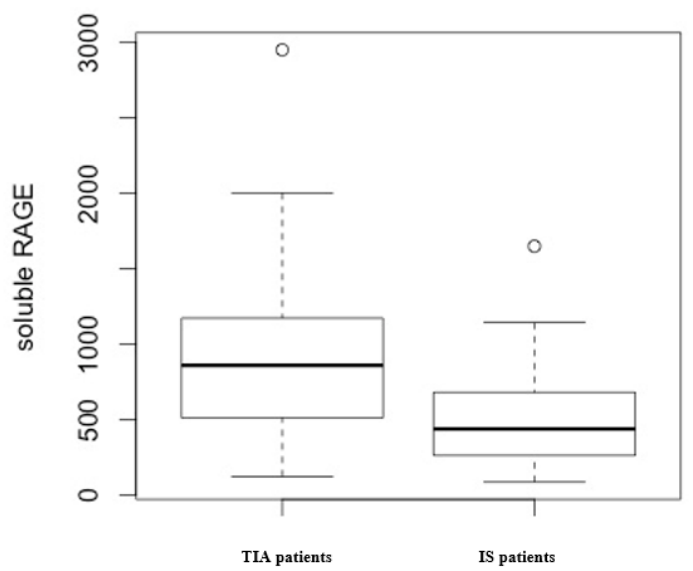

Figure 1. Box-plot representation of sRAGE plasma levels in TIA and IS patients. 
Table 2. Clinical and biochemical characteristics of the study participants divided according to their pathologies.

\begin{tabular}{|l|c|c|c|}
\hline & $\begin{array}{c}\text { TIA patients } \\
(\mathbf{n}=\mathbf{6 4})\end{array}$ & $\begin{array}{c}\text { Stroke patients } \\
(\mathbf{n = 2 3 )}\end{array}$ & p value \\
\hline Age (mean \pm DS) & $68 \pm 12$ & $66 \pm 9$ & $\mathrm{Ns}$ \\
\hline Male, n (\%) & $30(47 \%)$ & $20(87 \%)$ & 0.0048 \\
\hline CAD, n (\%) & $39(61 \%)$ & $10(44 \%)$ & $\mathrm{Ns}$ \\
\hline Arithmic, n (\%) & $4(6 \%)$ & $1(4 \%)$ & $\mathrm{Ns}$ \\
\hline DCM, n (\%) & $13(20 \%)$ & $9(39 \%)$ & $\mathrm{Ns}$ \\
\hline None, n (\%) & $8(13 \%)$ & $3(13 \%)$ & $\mathrm{Ns}$ \\
\hline Hypertension, n (\%) & $52(81 \%)$ & $14(61 \%)$ & $\mathrm{Ns}$ \\
\hline Ever-Smoking, n (\%) & $33(51 \%)$ & $10(44 \%)$ & $\mathrm{Ns}$ \\
\hline Diabetes, n (\%) & $16(25 \%)$ & $7(30 \%)$ & $\mathrm{Ns}$ \\
\hline Total Cholesterol (mean \pm DS) & $5.17 \pm 1.21$ & $5.25 \pm 0.83$ & $\mathrm{Ns}$ \\
\hline HDL Cholesterol (mean \pm DS) & $1.27 \pm 0.34$ & $1.19 \pm 0.18$ & $\mathrm{Ns}$ \\
\hline Triglycerides (mean \pm DS) & $1.5 \pm 0.85$ & $1.4 \pm 0.9$ & $\mathrm{Ns}$ \\
\hline CRP (mean \pm DS) & $1,69 \pm 2$ & $0,91 \pm 1$ & $\mathrm{Ns}$ \\
\hline Soluble RAGE median (IQrange) & $859(512-1172)$ & $438(269-679)$ & 0.007 \\
\hline
\end{tabular}

patients with IS [438 (269-679) pg/mL] than in TIA patients [859 (5121172) $\mathrm{pg} / \mathrm{mL}] ; \mathrm{p}=0.007$.

\section{Relationship between sRAGE and laboratory parameters}

Using Spearman's correlation, we examined the association of sRAGE levels with baseline clinical and biochemical features of the study participants. Concentrations of sRAGE were not associated with age, male sex, blood pressure parameters, diabetes, current smoking or hsCRP.

\section{Discussion}

This analysis contributes information about the pathophysiology of vascular cerebral disease and, in particular, these results reaffirm strong prothrombotic and inflammatory components to the pathophysiology of ischemic stroke. The most pressing problems to be solved are to identify as early as possible the individual susceptibility to different damaging stimuli and to assess the relevance of possible protective factors.

sRAGE is a novel biomarker that is inversely associated with coronary atherosclerosis. It is a soluble receptor produced by alternative splicing of RAGE mRNA and it is abundantly present in the circulation [8]. Because sRAGE has been shown to successfully bind to AGEs it has been postulated that this soluble isoform could play an antagonistic role by competing with the cell surface receptor, thus preventing the adverse effects of RAGE signaling [9]. RAGE expression plays a key role in initiation and acceleration of atherosclerosis in both diabetics and nondiabetics. A previous study by Falcone et al. was the first to attempt to better define the role of sRAGE in humans [10]. In that case-control study of middle-aged, Italian, non-diabetic men, plasma sRAGE levels were lower in men with Coronary Artery Disease (CAD) than in those without $\mathrm{CAD}$, indicating the anti-inflammatory role of sRAGE. Most human studies have shown that the plasma levels of RAGE are lowers in subjects with cerebrovascular dementia, or individuals at high risk of cardiovascular disease [11-14], but contradiction data have also been reported [15-19]. In our previous work, CAD patients presenting with Peripheral Artery Disease (PAD) have lower sRAGE levels than CAD patients without peripheral atherosclerosis showing that stable atherosclerotic lesions in different vascular districts are inversely related to soluble levels of decoy receptor sRAGE [20]. The present study strengthens our previous findings, reaffirming the role of sRAGE in human atherosclerosis.
In particular, the present study shows that the plasma concentration of sRAGE is significantly lower in patients with IS compared to patients with TIA and to controls.

Previous studies, conducted in patients with stroke, showed that soluble RAGE increase in serum after ischemic and hemorrhagic stroke as respect to control population [7,21] and identified low levels of sRAGE in the blood of intracerebral hemorrhagic patients compared with those presenting ischemic stroke [22]. The differences of sRAGE levels among different stroke subtypes could be related to acute stroke severity rather than different etiologies of the stroke subtypes [23].

Efforts to study the production of endogenous sRAGE seem justified by the possibility of new and innovative therapies against atherosclerosis and other inflammatory diseases [24]. Intravenous administration of sRAGE may capture and eliminate circulating RAGE ligand, thus acting as a decoy receptor and protecting against tissue damage. Systemic administration of sRAGE may be an effective therapeutic approach for all RAGE-mediated vascular disorders [23].

\section{Conclusion}

In conclusion, our research show that lower levels of sRAGE are associated with the presence of atherosclerotic disease conditioning stroke, confirming the presence of low levels of sRAGE in patients with atherosclerotic disease, as we had previously described. On the contrary, higher levels of this protein are observed in patients with TIA, confirming the non organic genesis of this pathology. The estimate of sRAGE could be an important complement to the determination of other inflammatory molecules, also critically associated with inflammatory responses and adaptation primitives, including those associated with atherosclerosis. The sRAGE evaluation in patients with neurological deficits may be useful to discriminate patients with atheromasic disease from those with functional pathology. Future studies are needed to further examine how different levels of the soluble form of RAGE could influence atherosclerosis and cerebrovascular inflammation.

\section{Conflicts of interest}

The authors declare that there is no conflict of interest.

\section{References}

1. World Health Organization. World Health Report 2010. Geneva, Switzerland: World Health Organization 2010.

2. Easton JD, Saver JL, Albers GW, Alberts MJ, Chaturvedi S, Feldmann E, et al (2009) Definition and evaluation of transient ischemic attack: a scientific statement for healthcare professionals from the American Heart Association/American Stroke Association Stroke Council; Council on Cardiovascular Surgery and Anesthesia; Council on Cardiovascular Radiology and Intervention; Council on Cardiovascular Nursing; and the Interdisciplinary Council on Peripheral Vascular Disease. The American Academy of Neurology affirms the value of this statement as an educational tool for neurologists. Stroke 40: 2276-2293.

3. Kalea AZ, Schmidt AM, Hudson BI (2009) RAGE: a novel biological and genetic marker for vascular disease. Clin Sci (Lond) 116: 621-637. [Crossref]

4. Yan SF, Ramasamy R, Schmidt AM (2010) The RAGE axis: a fundamental mechanism signaling danger to the vulnerable vasculature. Circ Res 106: 842-853. [Crossref]

5. Ramasamy R, Yan SF, Schmidt AM (2009) RAGE: therapeutic target and biomarker of the inflammatory response--the evidence mounts. J Leukoc Biol 86: 505-512. [Crossref]

6. Chavakis T, Bierhaus A, Al-Fakhri N, Schneider D, Witte S, et al. (2003) The pattern recognition receptor (RAGE) is a counterreceptor for leukocyte integrins: a novel pathway for inflammatory cell recruitment. $J$ Exp Med 198: 1507-1515. [Crossref]

7. Menini T, Ikeda H, Kimura S, Gugliucci A (2014) Circulating soluble RAGE increase after a cerebrovascular event. Clin Chem Lab Med 52: 109-116. [Crossref]

8. Lindsey JB, Cipollone F, Abdullah SM, McGuire DK (2009) Receptor for advanced 
glycation end-products (RAGE) and soluble RAGE (sRAGE): cardiovascular implications. Diab Vasc Dis Res 6: 7-14. [Crossref]

9. Santilli F, Vazzana N, Bucciarelli LG, Davì G (2009) Soluble forms of RAGE in human diseases: clinical and therapeutical implications. Curr Med Chem 16: 940-952. [Crossref]

10. Falcone C, Emanuele E, D’Angelo A, Buzzi MP, Belvito C, et al. (2005) Plasma levels of soluble receptor for advanced glycation end products and coronary artery disease in nondiabetic men. Arterioscler Thromb Vasc Biol 25: 1032-1037. [Crossref]

11. Emanuele E, Angelo DA, Tomaino C, Binetti G, Ghidoni R, Politi P, et al. (2005) Circulating levels of soluble receptor for advanced glycation end products in Alzheimer disease and vascular dementia. Arch Neurol 62: 1734-1736.

12. Geroldi D, Falcone C, Emanuele E, D'Angelo A, Calcagnino M, et al. (2005) Decreased plasma levels of soluble receptor for advanced glycation end-products in patients with essential hypertension. J Hypertens 23: 1725-1729. [Crossref]

13. Devangelio E, Santilli F, Formoso G, Ferroni P, Bucciarelli L, et al. (2007) Soluble RAGE in type 2 diabetes: association with oxidative stress. Free Radic Biol Med 43 : 511-518. [Crossref]

14. Santilli F, Bucciarelli L, Noto D, Cefalù AB, Davì V, et al. (2007) Decreased plasma soluble RAGE in patients with hypercholesterolemia: effects of statins. Free Radic Biol Med 43: 1255-1262. [Crossref]

15. Nin JW, Jorsal A, Ferreira I, Schalkwijk CG, Prins MH, Parving HH, et al. (2010) Higher plasma soluble Receptor for Advanced Glycation End Products (sRAGE) levels are associated with incident cardiovascular disease and all-cause mortality in type 1 diabetes: a 12-year follow-up study. Diabetes 59: 2027-2032.

16. Colhoun HM, Betteridge DJ, Durrington P, Hitman G, Neil A, Livingstone S, et al. (2011) Total soluble and endogenous secretory receptor for advanced glycation end products as predictive biomarkers of coronary heart disease risk in patients with type 2 diabetes: an analysis from the CARDS trial. Diabetes 60: 2379-2385.
17. Nakamura K, Yamagishi S, Adachi H, Matsui T, Kurita-Nakamura Y, Takeuchi M, et al. (2008) Circulating advanced glycation end products (AGEs) and soluble form of receptor for AGEs (sRAGE) are independent determinants of serum monocyte chemoattractant protein-1 (MCP-1) levels in patients with type 2 diabetes. Diabetes Metab Res Rev 24: 109-114.

18. Koyama Y, Takeishi Y, Niizeki T, Suzuki S, Kitahara T, et al. (2008) Soluble Recepto for advanced glycation end products (RAGE) is a prognostic factor for heart failure. $J$ Card Fail 14: 133-139. [Crossref]

19. Nakamura K, Yamagishi S, Adachi H, Kurita-Nakamura Y, Matsui T, Yoshida T, et al. (2007) Elevation of soluble form of receptor for advanced glycation end product (sRAGE) in diabetic subjects with coronary artery disease. Diabetes Metab Res Rev 23: $368-371$.

20. Falcone C, Bozzini S, Guasti L, D'Angelo A, Capettini AC, et al. (2013) Soluble RAGE plasma levels in patients with coronary artery disease and peripheral artery disease. Scientific World Journal: 584504. [Crossref]

21. Park HY, Yun KH, Park DS (2009) Levels of Soluble Receptor for Advanced Glycation End Products in Acute Ischemic Stroke without a Source of Cardioembolism. J Clin Neurol 5: 126-132. [Crossref]

22. Montaner J, Mendioroz M, Delgado P, García-Berrocoso T, Giralt D, Merino C, et al. (2012) Differentiating ischemic from hemorrhagic stroke using plasma biomarkers: the S100B/RAGE pathway. $J$ Proteomics 75: 4758-4765.

23. Tang SC, Wang YC, Li YI, Lin HC, Manzanero S, et al. (2013) Functional role of soluble receptor for advanced glycation end products in stroke. Arterioscler Thromb Vasc Biol 33: 585-594. [Crossref]

24. Geroldi D, Falcone C, Emanuele E (2006) Soluble receptor for advanced glycation end products: from disease marker to potential therapeutic target. Curr Med Chem 13 1971-1978. [Crossref]

Copyright: (C2017 Colomba F. This is an open-access article distributed under the terms of the Creative Commons Attribution License, which permits unrestricted use, distribution, and reproduction in any medium, provided the original author and source are credited. 